\title{
Research on High Power Microwave Weapons
}

\author{
Guoqi $\mathrm{Ni}^{1}$ Benqing $\mathrm{Gao}^{2}$ Junwei $\mathrm{Lu}^{3}$ \\ 1\&3. School of Microelectronic Engineering of Griffith University, Brisbane 4122 Australia \\ 2. School of Electronic Engineering of Beijing Institute of Technology, Beijing 100081 China
}

\begin{abstract}
This article describes for high power microwave (abbreviation HPM) weapons research from its procedures and developing trends. In the process of researching, developing and using weapons, we have been seeking a real "multi-purpose" weapon which is able to attack the overall target, suitable in all climates and on multi-platform carrier, both for battle field and peace keeping operations. As a result of over twenty years of research, HPM weapons are found to be the optimum answer for all the questions.
\end{abstract}

\section{I . INTRODUCTION}

The development of modern electronic technology, especially the continuous breakthrough of the key technologies in micro-electronics in recent years have made large-scaled integrated circuit and super high speed integrated circuit widely used in various weapon systems, and produced new, precise, compact and intelligence weapons. It is imperative to develop a new generation of weapon, because conventional weapons is not longer capable to deal with the complex electronic equipment and advanced technologies. Then high power microwave weapons arise. It is one of significant achievements in the application of microwave technology at the end of last century. It is still at the stage of trail production and preliminary equipment, but there is no doubt that it will become a favorite in future war as of its significant and outstanding characteristics on operational effects [1]. So the world developed countries have focused on the investigation of high power microwave weapon. It has been developed very fast in United States, Great Britain and Russia, it has been equipped to troops on a trial basis, and especially the United States tested it in Iraqi War and made it consummate in Kosovo war. This article reviews the process of the study in high power microwave weapons and prospects for its developing trends, in the purpose of making people give enough attention to the power of high-powered microwave weapons and developing a new method and technology of effective defense in the near future.

\section{II . The Process of Research \& DeVElopment OF High POWER MicRoWAVE WEAPONS}

High power microwave means the radio electromagnetic wave which peak power of microwave source is at $100 \mathrm{MW}$ $\sim 100 \mathrm{GW}$ and operating frequency is at $1 \sim 300 \mathrm{GHz}$. In this article, "HPM" is an abbreviation of High Power Microwave. The principle to destroy electronic devices via HPM is like thunder and lighting, the electronic devices is blasted by extreme strong electromagnetic pulse through "front door" and "rear door" [2]. "Front door" is a path which equipment uses to open up towards outside (e.g. antennas). Strong electromagnetic pulse is directionally guided to the targeted equipment to make its operation performance malfunctioned or deactivated completely. If the receiving frequency is known, via ingenious design, much worse destructiveness can be done. "Rear door" means leads, power cables, telephone lines, damaged shielded parts and even the holes on shielding case, through which standing wave energy can couple into and damage the equipment. Human exposure to HPM radiation is hazardous: HPM has heat effect and non-heat effect on human body. Microwave energy's heat effect which causes the living organization to produce heat, to be burnt or killed, the low energy microwave radiation is hazardous to human too, known as non-heat effect. Scientists conclude that low energy microwave is harmful to the human health; it may cause neurasthenia and heart blood vessel system disorder.

Characteristic of HPM mainly include: a). It can attack various targets. It not only damages electronic equipment in weapon systems, but also destroys them; not only makes people temperately loss their operating abilities, but also harms or even kills them. b). It can be used in many ways. It not only can be used as directional finding weapon and hit the targets accurately, but also destroy a mass of electronic equipment parlaying the whole systems. c). It can be used in all kinds of weather. Microwave can propagate in clouds, dust, mist and rain in the sky. d). It is a three dimension weapon, it not only can injury and kill the external personnel and do a great damage to electronic equipment on the ground, but also go through the internal of the targets to kill the inside hiding personnel, evermore, it can penetrate through the targets, kill the personnel who are concealing in a enclosed position and inside armored vehicles, no one can escape its "evil hands". e). It can be carried on multi-platform. It can be built in cruise missile warheads, unmanned airplanes, or installed on a fixed platform.

\section{A. Research and Development of HPM Sources}

As early as the nineteenth century, physicist Hertz considered electromagnetic wave to be a very power source and able to be used by the human beings.

Before World War II, it was assumed that electromagnetic wave could be used to destroy airplanes; as a result of the study, radar system was unexpectedly born. 
In 1970's, the development of pulse power technology and of diode based on negative pole field emitting and generating strong current electronic beams made great contribution to the revolutionary process in the produce of high power electronic beams, it provides good quality, large powered and high energy intense current pulse electronic beam source to the $\mathrm{R}$ \& D of HPM source, and it makes possible to reach unprecedented power level in research and development of new types of intense current relativity microwave devices and generation of coherent electromagnetic radiation from centimeter wave to millimeter wave. In order to peacefully use nuclear technology, develop new energy source and satisfy the human's demand in new energy, controllable nuclear fusion becomes a hot topic on the scientific forums, thus the relevant research and experiments of plasma physics theory was started. Through many tests and demonstration, the electromagnetic wave simulation and restriction of inertia nuclear fusion has been known. With the fast movement of high density physics study, pulse power technology is used in electromagnetic applications. Under the influence of nuclear research, the marriage between plasma physics and pulse power technology is happened, the microwave weapon is accordingly produced. With pulse power, scientists can generate relativity charged particles at $10 \mathrm{KA}, 1 \mathrm{GW}$ or even higher power. A relativity electronic beam means the one which has electronic energy at over $510 \mathrm{keV}$, and can be used to supply high power microwave. A relativity electronic beam can be introduced into HPM devices such as magnetron, cyclotron tube and traveling-wave tube, making microwave have the characteristic of effective output frequency adjustment which is changing accordingly with particle energy. Later on, virtual cathode oscillator and relativity klystron appeared. All the above have established the foundation of microwave weapons in theory, have proven the feasibility of using microwave as weapon in technology, and it is ready for the search and development of microwave weapon devices [3].

Former Soviet Union was the first who successfully developed HPM weapon, and was far ahead of other countries on the research of HPM source especially. But USA catches up and surpasses it becoming the leader in this area after the separation of former Soviet Union. Table 1 shows capability target of part HPM. In the blow table, $\mathrm{P}=$ Power, $\mathrm{F}=$ Frequency, $\tau=$ Pulse Width, $\eta=$ Converting effectiveness. The fig. 1 shows relationship both power and frequency of partly HPM device .

\section{B. Research and Development of HPM Weapon System}

In the beginning of Gulf War in 1991, in the sky above Baghdad, once appeared a mysterious stealthy "F-117"airborne cruise missile, on which USA installed "experimental tactical microwave missile warhead". After the explosion, a large variety of Iraqi military electronic equipment near the blast site suddenly was disabled. The overall electronic equipment seemed neither damaged, nor suffered from electronic interference and compression, but some of electronic devices inside of the Iraqi electronic equipment
TABLE I

CAPABILITy TARget of PART HPM

\begin{tabular}{|c|c|c|c|c|c|}
\hline $\begin{array}{l}\text { Name of HPM } \\
\text { device }\end{array}$ & $P(G W)$ & $\mathrm{F}(\mathrm{GHz})$ & $\tau(\mathrm{ns})$ & $\begin{array}{l}\eta \\
(\%)\end{array}$ & National \\
\hline $\begin{array}{l}\text { Virtual cathode } \\
\text { oscillator }\end{array}$ & 1.2 & 5.9 & & & America \\
\hline $\begin{array}{l}\text { Freedom } \\
\text { electronic laser }\end{array}$ & $>1$ & 40 & & 30 & America \\
\hline $\begin{array}{l}\text { Axial driven } \\
\text { cathode } \\
\text { oscillator }\end{array}$ & 7.5 & 1.17 & & & America \\
\hline $\begin{array}{l}\text { Plasma } \\
\text { auxiliary slow } \\
\text { wave oscillator }\end{array}$ & $4-8$ & & & $\begin{array}{l}15- \\
25\end{array}$ & America \\
\hline $\begin{array}{l}\text { Single pulse } \\
\text { looping-wave } \\
\text { oscillator }\end{array}$ & 1.5 & $8-12.5$ & 60 & 30 & $\begin{array}{l}\text { Soviet } \\
\text { Union }\end{array}$ \\
\hline $\begin{array}{l}\text { Looping-wave } \\
\text { oscillator }\end{array}$ & 1 & 10 & 2 & 30 & $\begin{array}{l}\text { Soviet } \\
\text { Union }\end{array}$ \\
\hline $\begin{array}{l}\text { Field radiation } \\
\text { oscillator }\end{array}$ & 0.06 & 7 & & 25 & $\begin{array}{l}\text { Soviet } \\
\text { Union }\end{array}$ \\
\hline $\begin{array}{l}\text { Looping-wave } \\
\text { oscillator }\end{array}$ & 1.5 & $\mathrm{X}$ band & 60 & 50 & Russian \\
\hline $\begin{array}{l}\text { Repeating pulse } \\
\text { looping-wave } \\
\text { oscillator }\end{array}$ & 1 & 10 & 2 & 30 & Russian \\
\hline $\begin{array}{l}\text { Relativity } \\
\text { magnetron }\end{array}$ & 0.1 & & 1000 & & Russian \\
\hline $\begin{array}{l}\text { Improved } \\
\text { cyclotron tube }\end{array}$ & 2 & 12.5 & 50 & & Russian \\
\hline $\begin{array}{l}\text { Polarized } \\
\text { radiation } \\
\text { microwave tube }\end{array}$ & 0.06 & 7 & 700 & 25 & Russian \\
\hline
\end{tabular}

\section{Peak Power $(\mathrm{GW})$}

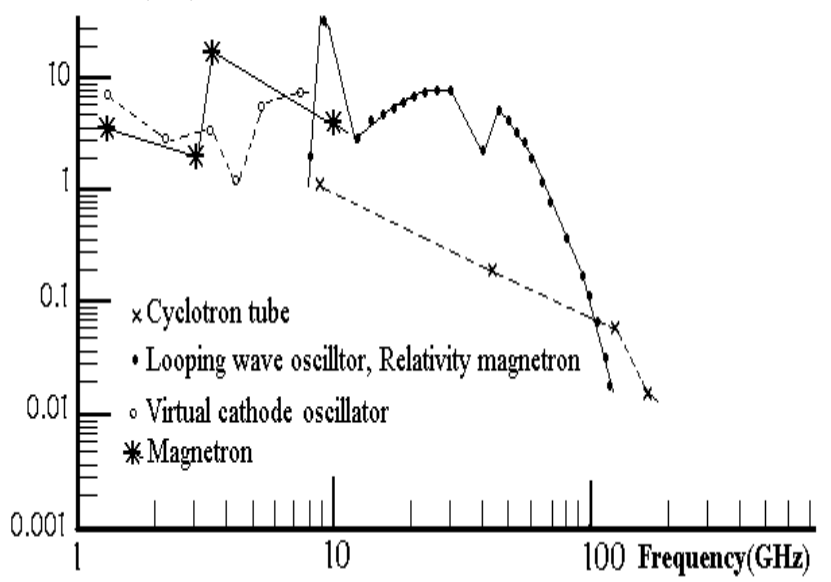

Fig. 1. The relationship both power and frequency of partly HPM device

were mysteriously destroyed. It indicates that US is leading the world in the design, research and development of military microwave weapons, which is nearly ready to be used in real time war. It also shows that the research and development of HPM has entered into a period of practical exercise[4][5].

USA is not only conducting HPM weapons, but also focusing on the study and development of microwave bomb and microwave missile warhead. For example, a new type of air-drop HPM bomb has been manufactured in nuclear weapon institute, Department of Energy of America. This bomb is designed to destroy the electronic equipment on the 
mobile intercontinental ballistic missiles with wideband frequency microwave radiation. Boeing has produced a HPM bomb to damage the electronic equipment installed on the enemy's tanks.

Former Soviet Union was the earliest country to start the HPM weapon research, which already tested microwave weapon by transmitting microwave into spherically stratified ionosphere, to interfere radio communication and make radar useless. Among their research results, the most successful and mature product is the defense purposed HPM weapon sample. The fig. 2 shows the component and relationship of three conventional heavy duty trucks of the HPM weapon. This weapon radiates $1 \mathrm{GW}$ of microwave. When the killing effective range is $1 \mathrm{Km}$, the target energy density is at $400 \mathrm{~W} / \mathrm{cm}^{2}$. when the killing distance is $10 \mathrm{Km}$, the target energy density is $4 \mathrm{~W} / \mathrm{cm}^{2}$. It can make the enemy's striking planes loss control of aviation electronic equipment and targeting systems, deactivate the anti-radiation missile warhead and make the air cruise missiles and other bombs loss operational abilities.

Russian today's success is based upon the research of the scientists in former Soviet Union, keeping them not falling behind the Americans. The Russian scientists built a "desk size" explosive flux compression generator inside the weapon, which can convert explosion energy into powerful electromagnetic pulse wave. The test shows that it provides 100MJ "single emitting" microwave energy. Now Russia is studying and testing a ground based RF weapon for the purpose of destroying satellites, and also is developing a HPM weapon aiming to paralyze all the modern and advanced defense systems in western countries. Its released energy is assumed to be able to destroy the radar systems and solid nerve systems of $\mathrm{C}^{3} \mathrm{I}$ system along the overall NATO borders.

In September 2001, Russian Rosoboron Export Company exhibited a called "Ranets-E" mobile microwave RF beaming system, which can reduce the weapon accuracy within $10 \mathrm{Km}$ of distance. It can rotate $360^{\circ}$, elevate from $0^{\circ}-60^{\circ}$ to destroy the electronic equipment inside the accurately guided weapons, it also can protect important military facilities from being attacked by the enemy's accurately guided weapons, it also can protect important military facilities from being attacked by the enemy's accurately guided weapons. It consists of antenna subsystem, high power generator, detecting and controlling equipment as well as power source subsystem. It has two models, one is fixed and the other is mobile. It operates in centimeter band; the power output is over $500 \mathrm{MW}$, the transmitting pulse width is $10-20 \mathrm{~ns}$.

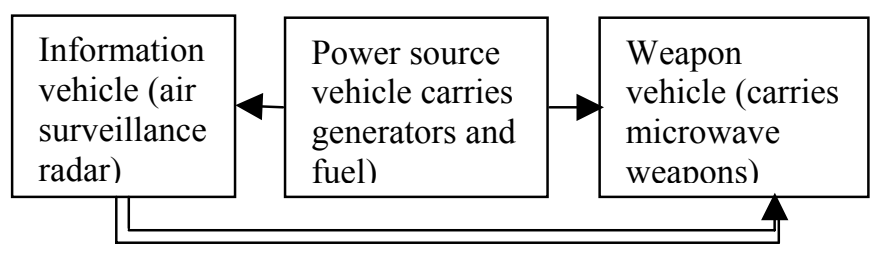

Fig. 2 Component and relationship of the HPM weapon of Soviet Union

\section{TREnds ANd Potential Directions of HPM WeAPONS}

\section{A. Trends of HPM Weapons}

a. Compactness of HPM source. It will include 4 times of increase in output power of super-wide band source, 6 times of increase in narrow band pulse length, up to one frequency multiplying range at narrow band source adjustment, about $227 \mathrm{Kg}$ at weight and $0.0425 \mathrm{~m}^{3}$ at volume (excluding antenna and pulse power source) .

b. Antenna will be of smaller aperture, high power, high gain, super-wide band and intelligence. It will include decreased to 18 inches in antenna aperture and about $15-20 \mathrm{db}$ of antenna gain. The effect of HPM weapons with intelligence antenna is the best for the antagonism equipments of radiating microwave.

c. Pulse power driver will be more compact, higher effective and more power. It is required that the volume is smaller than $0.28 \mathrm{~m}^{3}$, weight about $227 \mathrm{Kg}$ and high peak power greater than $50 \mathrm{GW}$.

d. HPM weapons can be researched by computer simulation. At present, many experiments on microwave theory and technology are being researched by computer simulation. For example, designed of antenna is simulated by using HFSS software, and electromagnetic compatibility researched is simulated by FEMLAB software, and so on[6].

e. High power microwave effectiveness and antipersonnel ability. It includes the RF tests on various of air, sea, ground, air-space military equipment; the development and establishment of RF effect, and on the analogy of which, to other equipment and systems, bringing forth new ideas of resistance technologies and applying HPM to the equipped military weapons in battle field; assuring the safety of personnel and estimating the valve value of necessary living objects' effects.

f. Satisfying the system integration requirement of military platform. It will include integration and installation of pulse power driver, HPM source and output antenna onto fixed or rotary, airplane, Navy ships, vehicles, plane's hanging containers, unmanned aircraft, munitions and other military platforms.

g. According to the electromagnetic interference from both sides of HPM weapons. It will be studied our side of enforcement measurement inside the equipment and system, which includes transferring the electromagnetic enforcement measurement to the end users and let them solve the going problems of electromagnetic interference and electromagnetic capability as well as forecast the threat; judging the sensitivities in air, ground, sea, space and key American military systems; developing the enforced resistant measurement with the minimum impact on system performance, expenses and maintenance.

h. Additional application evaluation. Evaluation is based upon the effect valuation and technology development. If it can be use in other areas in the future besides the application in military, it is being considered to use in air-ground missile defense and space control. The evaluation requires the technical demonstration in an appropriate situation. 
In conclusion, The major developing trends of HPM weapons are: The first, to combine with accurately guided weapons in order to reduce the requirement for transmitting power of high powered weapons thus gaining the compact size; The second, to increase the effective attacking range and effectiveness on battlefield, these can be achieved by the means of (1) integration with unmanned aircraft; (2) with the improvement of antenna aperture and motor-driven performance, to be able to continuously increases the effective attacking range; The third, studying of re-usability to reduce the costs of battles. On an aviatid(4)exhibition, some of companies had proposed the concept of re-usable cruise missile. If successful, it will help to reduce the carrier costs of HPM weapons; The forth, combining the functions of injuring people and of destroying equipment together, and being able to be flexibly controlled by the operating personnel. By adjusting the transmitting energy power, to determine the appropriate level of energy to achieve the desired effects and decide the level of injuring the enemy's personnel and destroying the weapons.

\section{B. Potential Directions of HPM Weapons}

a. Studying from the way of its generation. The initial study was intended to wrap the highly explosive munitions around the electro-field coil to supply a blast of high power microwave while the explosion. US Air Force once tested the technology on particularly modified air-borne cruise missile warhead, but the plan was abandoned because of the directionally focusing and non-effective range problems. Another study adopted a new generation of capacitors intending to concentrate the energy pulse in the front of missile warhead to a very narrow arc area while energy being release. Unmanned aircraft is an ideal platform for carrying HPM weapons, which will not cause any danger to pilots and has much higher accuracy.

b. Studying from the desired effect, i.e. the level of injuring and killing. One direction of the study is specifically testing non-lethal microwave weapons to interfere, damage the enemy's electronic and technological equipment and systems. The other direction of the study is emphasizing on antipersonnel microwave weapons, which has high power and can cause destructive effects upon the enemy's vessels, aircrafts and missiles.

c. Studying for the way of use. It is mainly focused on once off and re-use. Once off use is for single pulse microwave bomb, which can be driven by conventional munitions or by nuclear explosion. Currently the conventional munitions driven method draws attention. It equips microwave bomb system and radiation antenna on the bomb (laser guided bomb) or missile (cruise missile) thus forming air-borne or bomb-borne microwave bomb. By using the way of munitions explosion compressing flux, the energy from munitions blast is converted into electric energy to supply electromagnetic pulse, via the special electromagnetic wave guided structure and convert the particles into wave energy, the electric energy is converted into electronic beam current which is then changed into microwave, finally emitted through the antenna. America is leading the use of once off use of microwave bomb, which is mainly installed on cruise missile warheads, and a sample of unmanned aircraft has installed this bomb as well.

Multiple pulse repeating transmitting devices consist of power source system, repeating frequency accelerator, high power microwave device and directionally guided transmitting system. The emphasis is on the HPM source. Multiple pulse repeating transmitting devices use common batteries, can re-target, and attack the same target many times. To use the pulse power source means to adopt the super speed circuit direct driven to supply nano-second level of super short pulse, thus gaining the super wide electromagnetic radiation output. Today's Russia takes advantage of former Soviet Union's development in high power oscillator technology leading the study of the re-use of microwave bomb. It has achieved $15 \mathrm{Km}$ of the effective attacking range for HPM beams transmitted from the fixed platform.

\section{CONCLUSIONS}

Due to classification restrictions, details of this work are relatively unknown outside the military community. The author in this article analyses the current available information and discusses it from several periods, the purpose is to encourage others coming up with valuable opinions.

\section{REFERENCES}

[1] Weise,Th.H.G.G. Jung,M. Langhans,D. Gowin,M., Overview of directed energy weapon developments, Electromagnetic Launch Technology 2004. 2004 12th Symposium on, 25-28 May 2005, pp.483-489.

[2] Jordan, U. Anderson, D. Backstrom etc, O., Microwave Breakdown in Slots, Plasma Science, IEEE Transactions on , Dec. 2004, Volume: 32 , Issue: 6, pp. $2250-2262$

[3] Meichu Guo, The High Technology Wars Sword \& Shield, Military Scientific Publishing House, Beijing, February 2003, Chap. 1.

[4] Schamiloglu, E., High power microwave sources and applications, Microwave Symposium Digest, 2004 IEEE MTT-S International , 6-11 June 2004 Volume: 2 , pp. 1001 - 1004 Vol.2

[5] Korovin, S. D. Rostov etc, Pulsed power-driven high-power microwave sources, Proceedings of the IEEE, July 2004 Volume: 92 , Issue: 7, pp. $1082-1095$

[6] Hou De-tin, Hu Tao etc, Numerical calculation of high power microwave propagation trace in atmosphere, Antennas, Propagation and EM Theory, 2003. Proceedings. 2003 6th International SYmposium on, 28 Oct.-1 Nov. 2003, pp. 520 - 523

[7] Lu Xun Hou De-tin Zhou Dong-fang etc, Research on high power microwave pulse in the air breakdown, Antennas, Propagation and EM Theory, 2003. Proceedings. 2003 6th International SYmposium on, 28 Oct.-1 Nov. 2003, pp.537 - 540. 